\title{
Gesamterneuerungswahl 2020 des Steuerungsausschusses der SAQM
}

\section{Roxane Kübler ${ }^{a}$, Esther Kraft ${ }^{\text {b }}$, Christoph Bosshard ${ }^{c}$}

a MA, Operative Leiterin der Schweizerischen Akademie für Qualität in der Medizin SAQM der FMH; 'b lic. rer. oec., Leiterin Abteilung Daten,

Demographie und Qualität DDQ der FMH; ${ }^{c}$ Dr. med., Vizepräsident der FMH, Departementsverantwortlicher Daten, Demographie und Qualität

Im Rahmen des nächsten Treffens des Forums Qualität der SAQM am 30. April 2020 findet die Gesamterneuerungswahl des Steuerungsausschusses der SAQM statt. Die Qualitätsdelegierten des Forums Qualität wählen dann vier Mitglieder für vier Jahre in den Steuerungsausschuss.

\section{Forum Qualität SAQM}

Das Forum Qualität stellt sicher, dass das fachspezifische und organisationsbezogene Wissen zu Qualitätsfragen in der Medizin berücksichtigt wird. Pro Jahr finden ca. zwei Treffen zu je vier Stunden in Bern statt. Für das Forum Qualität können folgende Organisationen je eine/n Delegierte/n und eine/n oder mehrere Ersatzdelegierte stellen: die Fachgesellschaften, die kantonalen Ärzteorganisationen, die Dachverbände, der Verband Schweizerischer Assistenz- und Oberärztinnen und -ärzte VSAO und der Verein der Leitenden
Spitalärzte der Schweiz VLSS. Wahlberechtigt sind alle Delegierten der Fachgesellschaften und der kantonalen Ärztegesellschaften mit der Stimmkraft von je einer Stimme. Die Delegierten der Dachverbände, des VSAO und des VLSS besitzen eine beratende Stimme. Die Wahlberechtigten des Forums Qualität wählen die vier Steuerungsausschussmitglieder für die Dauer von vier Jahren. Wählbar sind alle Mitglieder des Forums Qualität (Delegierte und Ersatzdelegierte) sowie die amtierenden Mitglieder des Steuerungsausschusses, sofern sie sich wieder zur Wahl stellen.

\section{? $F \mathbf{M H}_{A S Q M}^{\mathrm{SAOM}}$}

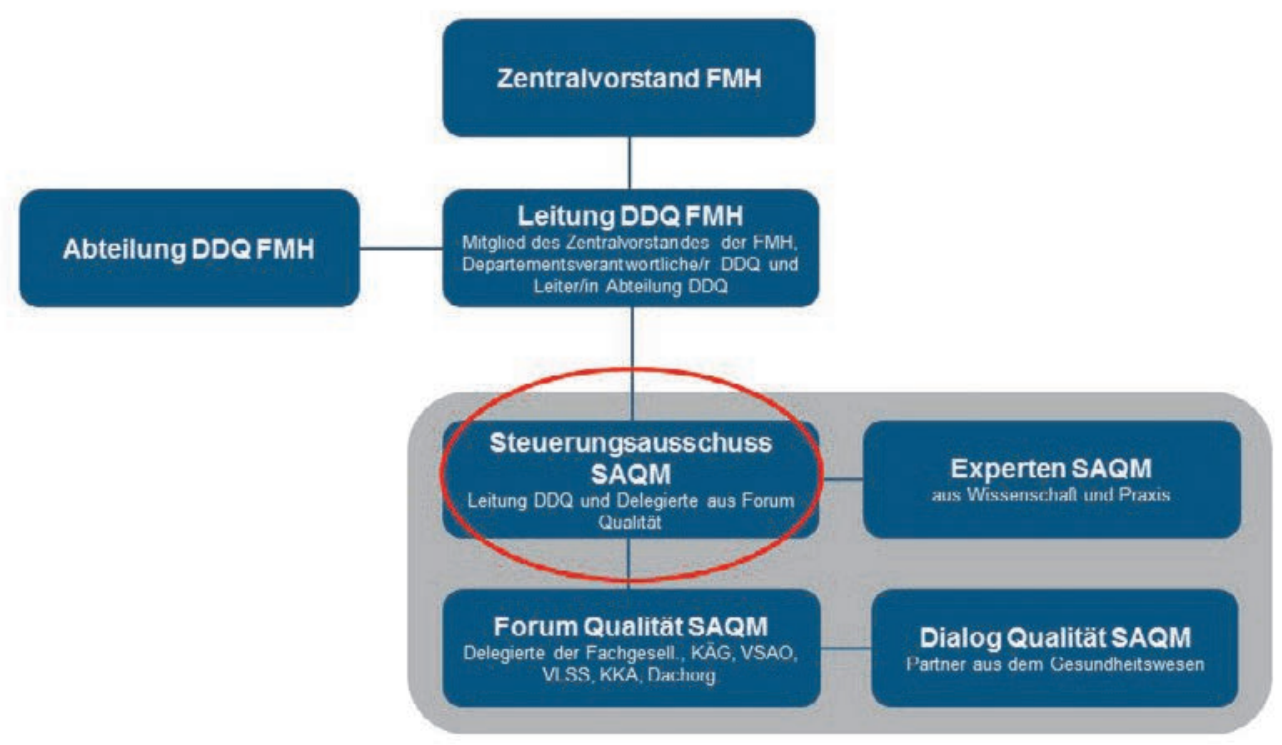




\section{Steuerungsausschuss SAQM}

Der Steuerungsausschuss der SAQM ist ein beratendes Organ für den Zentralvorstand der FMH. Er trägt die übergeordnete Verantwortung für alle SAQM-Projekte und die Begleitung SAQM-externer Projekte. Die Entschädigung der Mitglieder des Steuerungsausschusses erfolgt analog zur Entschädigung der Mitglieder von FMH-Kommissionen. Es finden jährlich ca. sechs Sitzungen, meistens in Bern, statt. Dazu kommen nach Möglichkeit die Teilnahme an den beiden jährlichen Treffen des Forums Qualität sowie den Treffen des Dialogs Qualität in Bern.

Der Steuerungsausschuss setzt sich zusammen aus dem amtierenden Departementsverantwortlichen der Abteilung Daten, Demographie und Qualität DDQ/ SAQM Dr. med. Christoph Bosshard und der Abteilungsleiterin der DDQ/FMH lic. rer. oec. Esther Kraft sowie aus vier gewählten Qualitätsdelegierten des SAQM-Gremiums «Forum Qualität».

Wichtig ist, dass die Mitglieder des Steuerungsausschusses ihre Aufgaben mit einem fach- und organisa- tionsübergreifenden Blick wahrnehmen, da sie nicht als Vertretung ihrer Ärzteorganisation, sondern ad personam gewählt werden. Gewählte Steuerungsausschussmitglieder geben daher ihren bisherigen Sitz im Forum Qualität ab. Dieser wird durch die betroffene Ärzteorganisation neu besetzt.

\section{Ihre Möglichkeit zur Kandidatur für den Steuerungsausschuss SAQM}

Wenn Sie Interesse an einer Kandidatur für den Steuerungsausschuss haben, bitten wir Sie, sich diesbezüglich mit Ihrer Ärzteorganisation bis spätestens 17. Februar 2020 in Verbindung zu setzen. Nur Ihre Ärzteorganisation kann Sie als Qualitätsdelegierte/n oder Ersatzdelegierte/ $\mathrm{n}$ in das Forum Qualität entsenden. Und nur als Qualitätsdelegierte/r oder Ersatzdelegierte/r einer Ärzteorganisation sind Sie in den Steuerungsausschuss wählbar.

Über Ihr Interesse würden wir uns sehr freuen und stehen für Fragen gerne zur Verfügung. 